\title{
A prática deliberada na prática: uma adaptação das teorias sobre aquisição de habilidades às especificidades da interpretação simultânea
}

\author{
Raquel Moniz de Aragão Schaitza*
}

Ao concluir um curso de formação em interpretação simultânea, o aluno ideal estará preparado para ingressar gradualmente no mercado, mas provavelmente ainda terá pela frente um longo caminho a trilhar até ser reconhecido como expert.

Esse caminho parece ter ficado mais claro desde que o artigo Expertise in Interpreting (2000), do psicólogo cognitivo K. Anders Ericsson, formalizou o encontro entre os estudos da interpretação e da psicologia da aquisição de habilidades. A partir de então, disseminou-se a ideia de que a conquista de expertise em interpretação pode ser comparada ao processo descrito por Ericsson para aquisição de outras habilidades por ele estudadas.

Se essa comparação for de fato possível, três conceitos importantes se aplicariam à aquisição da habilidade de interpretar.

O primeiro indica que um intérprete teria atingido o nível de expertise quando fosse capaz de reproduzir desempenho continuamente superior em um conjunto pré-definido de tarefas representativas da interpretação. (Ericsson, 1994, p. 730).

\footnotetext{
* Raquel Schaitza é Master of Advanced Studies em Formação de Intérpretes pela Universidade de Genebra, intérprete desde 1987 e formadora de intérpretes desde 2013 em Curitiba, no Paraná.
} 
O segundo sugere que o caminho mais produtivo para um iniciante se tornar um expert seria a prática deliberada. Ericsson (2013, p. 534) classifica como deliberada a prática focada em uma sequência de aspectos específicos da habilidade que se pretende dominar, seguida de feedback e de oportunidades de melhoria gradual por repetição e tentativa de solução de problemas.

O terceiro (Ericsson, 2013, p. 534) sinaliza que o tempo necessário para plena aquisição de uma nova habilidade costuma girar na casa de milhares de horas distribuídas ao longo de muitos anos.

A possível aplicabilidade desses conceitos à formação de intérpretes desperta algumas reações.

Em relação à definição de expertise, ignora-se a existência de um conjunto pré-definido de tarefas representativas de interpretação que, se bem realizadas repetidamente, serviriam para garantir que um intérprete terá desempenho reprodutível continuamente superior. Pelo contrário, mesmo intérpretes percebidos como experts admitem experimentar oscilações marcadas de desempenho, ou seja, a exigência de performance continuamente superior não parece realista no mundo da interpretação.

Quanto à aplicabilidade da prática deliberada à formação de intérpretes, intuitivamente faz sentido que uma habilidade complexa como a interpretação seja praticada pelo aluno não como um todo, mas em uma sequência de suas partes, com foco consciente na melhoria gradual.

Já o prazo para se atingir o nível de expertise aponta um horizonte demasiado longínquo até mesmo em cursos de interpretação que seguem o modelo do $\mathrm{EMCI}^{1}$ que preconiza aproximadamente 800 horas de instrução e prática cumpridas no prazo de um a dois anos.

Essas observações parecem convidar a uma reflexão mais profunda sobre a real aplicabilidade das teorias de Ericsson à interpretação.

\section{Como se mede desempenho em interpretação?}

Uma habilidade conhecida como a natação pode ser útil para ilustrar a dificuldade de medir desempenho em interpretação. Sabe-se que o

${ }^{1}$ European Masters in Conference Interpreting: http://www.emcinterpreting.org/?q=node/13 (acesso em 08/07/2017) 
desempenho de nadadores pode ser inequivocamente aferido com um cronômetro em competições sujeitas a regras rígidas, realizadas em piscinas com dimensões, volume de água e temperatura rigorosamente controlados.

Já na interpretação, não se tem notícia de um "cronômetro" capaz de medir o desempenho de um intérprete com precisão. Além disso, ao contrário da natação, é da natureza da interpretação que as condições a que o intérprete se sujeita não sejam padronizadas. Medições imprecisas em condições variáveis não parecem ser a maneira mais confiável de registrar os melhores desempenhos e, consequentemente, identificar experts em interpretação.

\section{Quais os componentes da habilidade de interpretar?}

A rigor, identificar um expert exige descrever suas características exatas e detalhar que componentes da habilidade de interpretar o iniciante não tinha, mas praticou de forma deliberada até atingir o nível de expertise.

Apesar de citar pesquisas anteriores de estudiosos da interpretação como Dillinger, Gerver, Lambert, Massaro, Shlesinger e Moser-Mercer, entre outros, Ericsson (2000) não considerou que a identificação então disponível dos componentes da habilidade de interpretar fosse satisfatória (p. 216).

Desde então, pesquisadores como De Groot (2000), Kalina (2000), Riccardi (2005), Jiang e Norvele (2007), Moser-Mercer (2008), Gile (2009), Liu (2009), Johnson (2011), MacNamara (2011), Barghout, Rosendo \& García (2015), só para citar alguns nomes, persistiram na tentativa de identificar esses componentes. Entretanto, apesar de uma certa convergência de opiniões, não se nota nem ao menos uma uniformidade terminológica entre eles.

Por fim, na mais abrangente obra sobre formação de intérpretes até hoje publicada, Setton e Dawrant (2016), ao apelar para o que consideram ser uma mera compilação da sabedoria coletiva revelada em estudos anteriores (p. 67), sinalizam que a falta de consenso persiste.

Nesse cenário de pouca clareza, a rigor não seria possível adotar o conceito de prática deliberada no ensino de interpretação, já que não se 
saberia exatamente que componentes da habilidade de interpretar devem ser praticados pelo aluno que pretende se tornar expert.

\section{Qual o tempo necessário para se atingir o nível de expertise em interpretação?}

Se, ao contrário da natação, o indeterminismo das condições de trabalho de um intérprete (McNamara, 2011) parece impossibilitar a aferição de desempenho em interpretação com precisão, qualquer avaliação de tempo para se atingir o nível máximo de performance seria mera conjectura.

Além disso, prazos de milhares de horas (Ericsson, 2013, p. 530) ultrapassam, em muito, a duração de um curso de formação de intérpretes, o que leva a concluir que a continuidade do progresso rumo à expertise se dará necessariamente de forma autônoma, fora da sala de aula.

\section{Outros olhares sobre a aquisição da habilidade de interpretar}

A inexistência de uma definição confiável de expertise em interpretação, a dificuldade de se decompor os vários processos da habilidade de interpretar e a imprecisão sobre o tempo necessário para um iniciante se tornar um intérprete expert constituem um convite à exploração de outros conceitos que possam complementar ou ajustar as teorias de Ericsson às especificidades da interpretação.

\section{O expert flexível}

Se mesmo intérpretes percebidos como experts admitem ser irreal reproduzir desempenho continuamente alto, sem oscilações independentemente da variabilidade de condições, a definição de expertise de Ericsson configura uma meta frustrante.

Entretanto, o próprio Ericsson (2013, p. 730) inclui a busca de soluções de problemas como elemento essencial da prática deliberada que poderá conduzir um iniciante ao nível de expertise e, de fato, resolver problemas continuamente faz parte da realidade da interpretação. A propósito, empiricamente, costuma se destacar como expert o intérprete capaz de encontrar as melhores soluções ao interpretar. 
Sendo assim, talvez a definição mais adequada à realidade da interpretação seja a do expert adaptativo de Hatano \& Inagaki (1986) citados por Moser-Mercer (2014, p. 8). Nessa visão, expert é aquele que se dedica à melhoria de desempenho durante toda a vida e acumula um arsenal de soluções eficazes às quais consegue recorrer rapidamente quando confrontado com um novo problema.

\section{O todo indivisível}

O conhecido Modelo dos Esforços de Gile (2009, p. 183), uma representação simples e acessível do processo de interpretar, indica a sucessão de três etapas supostamente equilibradas: uma mensagem original em um idioma é compreendida, passa por um processo de análise e depois é reformulada em outro idioma. Contudo, mesmo que essa sequência seja aparentemente óbvia, é impossível isolar e comprovar o peso desses esforços cognitivos na prática. Aliás, Shlesinger (2000, p. 6) alega que qualquer tentativa de decompor o processo indivisível de interpretar seria ecologicamente nula, pois não refletiria o que ocorre na realidade da interpretação onde separações e sequenciamentos não são perceptíveis, nem parecem possíveis.

Ocorre que a aplicação da prática deliberada ao ensino da interpretação exige que os componentes da habilidade de interpretar sejam identificados, isolados e sequenciados em complexidade ascendente (Ericsson, 1993, p. 290). Se isso é inviável, talvez duas visões alternativas permitam resgatar a validade pedagógica da prática deliberada.

A primeira vem de Merriënboer (1997) que propõe que os componentes de uma habilidade cognitiva complexa podem ser tratados como aspectos e não necessariamente como partes constitutivas isoláveis e sequenciáveis (p. 22). De fato, "aspectos" soa como um meio-termo mais satisfatório entre "componentes isolados" e "todo indivisível" para servir de base para estruturação de exercícios de prática deliberada na interpretação.

A segunda inspira-se em De Groot (2000) e pode trazer desdobramentos úteis não só para a estruturação da prática deliberada, como também para um dos gargalos do ensino de interpretação, que é a 
seleção de materiais adequados para prática. Por essa dupla vantagem, a abordagem de De Groot merece uma discussão mais aprofundada.

Cursos de interpretação costumam apelar para quatro fontes de material para atividades pedagógicas: professores atuando como oradores, alunos atuando como oradores, vídeos de repositórios criados especificamente para prática de interpretação e vídeos disponíveis online.

Apesar da utilidade inicial, os benefícios das três primeiras fontes de discursos pré-fabricados para alunos de interpretação se exaurem no curto prazo, pois dificultam o que Setton e Dawrant (2016) chamam de progressão baseada em realismo incremental (p. xxx TG).

Já os vídeos autênticos embutem características de realismo completo (Setton e Dawrant, 2016, p. xxxii TG), são ecologicamente válidos (Shlesinger, 2000) e, se abordados conforme sugerido por De Groot (2000), não necessariamente representam risco de sobrecarga cognitiva com consequente frustração e pânico para o aluno (p. 64).

O equilíbrio proposto por De Groot (2000) citando Gopher et al (1989) é expor o aluno a discursos autênticos, mas manipular a prática de forma a, em cada atividade, alternar a ênfase entre um e outro aspecto da interpretação simultânea, sem enfatizar todos em um mesmo exercício.

Ainda com base em experimentos de Gopher (1992), De Groot (2000) defende que essa prática manipulada com alternância de ênfase aumenta o nível de consciência de controle da atenção já que os problemas estão todos presentes, mesmo que alguns sejam temporariamente ignorados. Além disso, essa abordagem permite que o aluno aprenda a coordenar, como recomenda Gile (2009), os esforços necessários para o pleno cumprimento da tarefa de interpretar simultaneamente (p. 54).

Explorar outras teorias parece permitir concluir que a prática deliberada pode ser aplicada ao ensino de interpretação se o conceito básico de Ericsson (1993) for flexibilizado para admitir a prática consciente focada não necessariamente na melhoria de desempenho em componentes isolados e sequenciados, mas sim de diferentes "aspectos" (Merriënboer, 1997) abordados com "alternância de ênfase" inclusive em materiais mais autênticos (De Groot, 2000). 
Finalmente, vale observar que a flexibilização proposta não afeta os demais requisitos da prática deliberada preconizada por Ericsson (2013): feedback, oportunidades de repetição e busca de solução de problemas.

\section{Melhoria contínua}

Se admitirmos que a meta de um curso de interpretação seja formar experts adaptativos sempre dedicados à melhoria de desempenho, o aluno precisa se apropriar do processo de aprendizagem, adquirir as ferramentas necessárias para aumentar o arsenal de boas soluções para enfrentar o indeterminismo da interpretação na vida real (MacNamara, 2011) e continuar a evoluir mesmo quando não houver mais disponibilidade de um professor para dar feedback.

Para isso, segundo Moser-Mercer (2008) o ambiente de aprendizado deve encorajar a metacognição (Flavell, 1976) oferecendo ao aluno oportunidades de reflexão sobre como os problemas foram resolvidos e permitindo que assuma o controle sobre a própria evolução.

\section{Feedback e metacognição}

Ericsson (1993) deixa claro que a prática deliberada só trará resultados positivos se for seguida de feedback. Entende-se aqui por feedback a indicação da distância entre o nível atingido pelo aprendiz e desempenho percebido como característico de um expert, indicação essa que deve vir acompanhada de sugestões sobre como o aluno poderá superar essa distância. (Ramaprasad, 1983).

Sawyer (2004) descreve várias formas de feedback, todas válidas para fins de prática deliberada. $\mathrm{O}$ feedback formativo pode ser dado pelo professor ou por colegas e serve para confirmar se o desempenho foi satisfatório. A autoavaliação também é uma forma de feedback e pode tanto focar uma performance específica quanto, na modalidade ipsativa, se basear na comparação entre o desempenho atual e desempenhos passados. Todos esses formatos avaliam tanto processo, quanto produto. Já o feedback somativo concentra-se unicamente no produto e resulta em uma nota indicativa do nível de progresso atingido pelo aluno, tarefa nem sempre simples na interpretação onde medições objetivas não são óbvias. 
Ainda na linha de formação de experts adaptativos dedicados à melhoria contínua e busca permanente por um arsenal eficaz de soluções, todo feedback será mais produtivo se incentivar o aluno a aplicar estratégias metacognitivas (Moser-Mercer, 2008) ou, em termos leigos, a "pensar sobre como pensou" para avaliar se a estratégia adotada ao interpretar resultou, ou não, em soluções dignas de serem incorporadas ao arsenal do intérprete.

Estratégias metacognitivas podem ser aplicadas individualmente ou em grupos. Uma delas é a retrospecção ou a recapitulação, logo após a conclusão de uma atividade, do raciocínio aplicado à realização da tarefa proposta (Ericsson, 2003, p. 385). Outra abordagem metacognitiva inspirada em Ericsson (2000) é a conversação entre participantes de uma mesma atividade sobre as soluções adotadas por cada um. Essas conversas em grupo costumam revelar soluções desconsideradas individualmente. A metacognição pode também ser cultivada através da repetição de um mesmo exercício com a finalidade explícita de melhoria de um aspecto específico detectado como falho na primeira tentativa. Por fim, outro incentivo à metacognição é a comparação do desempenho do aluno com a performance de um expert na mesma atividade de forma a orientar o iniciante a fazer melhores escolhas no futuro (Ericsson, 2000).

A tecnologia atual oferece aplicativos e softwares de reconhecimento de voz, alguns deles disponíveis gratuitamente online, que permitem ao professor e/ou aluno transcrever e comparar detalhadamente o original à tradução com precisão até maior do que se consegue com gravações em duas faixas de áudio. Elimina-se assim o feedback baseado meramente em impressões (Setton, 2012) e, para fins metacognitivos, a transcrição pode ser utilizada para destacar os pontos dignos de melhoria que servirão de foco para um próximo exercício de prática deliberada.

Se adotadas como rotina, as atividades de feedback e metacognição levarão o aluno a desenvolver um olhar crítico e produtivo sobre seu próprio progresso, permitindo que ele se aproprie de seu desenvolvimento contínuo rumo à expertise em interpretação, mesmo após a conclusão da formação. 


\section{A prática na prática}

A proposta deste artigo é combinar as considerações acima e explorar como a prática deliberada com alternância de ênfase dos diferentes aspectos da interpretação, seguida de vários tipos de feedback e atividades de incentivo à metacognição, pode contribuir para que o aluno tenha maior controle sobre sua própria formação e esteja mais capacitado a generalizar e transferir o aprendizado para a vida profissional (Healey, Kole and Bourne, 2014), sempre com uma atitude de melhoria contínua.

Admitir a utilidade da prática deliberada implica contrariar a indivisibilidade de processos na interpretação defendida por Shlesinger (2000). Portanto, os gráficos sugeridos a seguir são uma mera tentativa pragmática de identificar em termos simples os vários aspectos da interpretação para fins pedagógicos.

Para o professor, a intenção é facilitar a estruturação de exercícios de prática deliberada. No entanto, foge ao escopo deste artigo sugerir exercícios específicos, pois cabe ao formador, conhecedor de seus alunos, pesquisar a literatura disponível e avaliar como os diferentes aspectos podem ser praticados, inclusive em atividades que podem nem envolver interpretação.

Para o aluno, os gráficos procuram atender a sugestão de Gile (2009, p. 245), para quem a apresentação de um conjunto restrito de conceitos e modelos teóricos de fácil entendimento pode resultar em maior eficiência didática. Esta também é uma forma de ajudar o aluno a desenvolver estratégias metacognitivas, pois aumenta a consciência sobre o que exatamente deve ser praticado, em especial após a formação, quando a prática será necessariamente autônoma.

Os gráficos propostos partem das etapas indicadas no Modelo dos Esforços (Gile, 2009) e, se lidos da esquerda para direita, pretende-se que sejam autoexplicativos. 


\section{Aspectos da fase de compreensão}

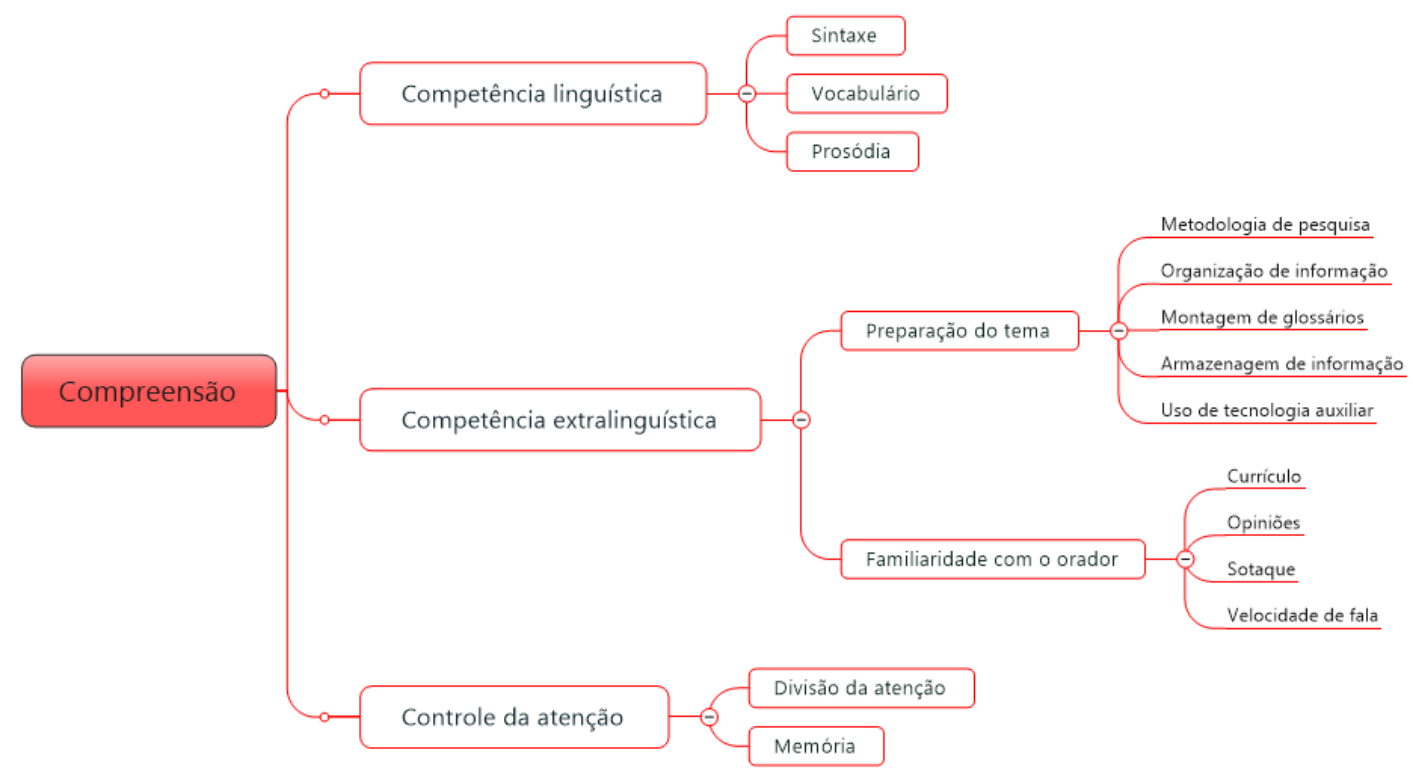

A compreensão depende, em primeiro lugar, de um alto nível de competência linguística que costuma ser considerada pré-requisito em cursos de interpretação. Portanto, em um cenário ideal, este não deve ser mais que um aspecto secundário na formação de intérpretes.

Já os aspectos de competência extralinguística merecem ênfase não só porque o aluno precisa aprender a lidar de forma produtiva com o volume de informação do mundo atual, mas também porque a tecnologia possibilita familiarização prévia, inclusive com as idiossincrasias da fala do orador. Outro benefício do desenvolvimento da competência extralinguística é atenuar o stress natural da interpretação simultânea, pois, com uma boa preparação, a compreensão passa a ser mais uma confirmação do que o aluno já esperava escutar do que um entendimento a partir do zero.

Por fim, a compreensão depende também do controle da atenção que provavelmente já terá sido abordado antes da introdução da interpretação simultânea, mas justifica-se um reforço de exercícios de divisão da atenção e memória sob a ótica da simultaneidade. 
Uma última observação sobre a prática da compreensão leva em conta a direcionalidade na interpretação. Em especial na escola europeia, a formação se inicia com exercícios de interpretação do idioma $\mathrm{B}$, apesar do stress naturalmente causado pelo déficit de compreensão, para o idioma A, onde existe um bônus de produção. No entanto, cogita-se aqui com base em Setton e Dawrant (2016, p. 244) que uma alternância de ênfase permitiria tanto diminuir o stress da compreensão, quanto alertar o aluno para uma necessidade real de certos mercados. Sob essa ótica, seria justificado tirar proveito do bônus da compreensão em A e, mesmo sob risco de déficit na produção, não adiar demasiadamente a introdução de prática deliberada para $\mathrm{B}$.

\section{Aspectos da fase de análise e tomada de decisão}

Análise e tomada de decisão

Percepção de conectores lógicos

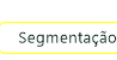

Os processos realizados nessa fase são tão imperceptíveis quanto essenciais na interpretação simultânea e o gráfico destaca aqueles tidos como mais produtivos para prática deliberada.

O primeiro é a apreensão da estrutura lógica do original. Práticas de consecutiva costumam incluir esse tipo de exercício para que o aluno perceba que "todo discurso é uma sequência de ideias em uma dada ordem" (Gillies, 2013, p. 7). A mesma linha de exercícios pode ser resgatada na prática deliberada de simultânea para automatizar no aluno o reflexo de segmentar a fala com base na identificação de conectores lógicos. As informações contidas em cada segmento serão, então, submetidas a um filtro que determinará se podem/devem ser mantidas na íntegra, resumidas, omitidas deliberadamente para evitar redundância ou acrescidas de explicações que facilitem a compreensão para o ouvinte final.

O segundo enfoque de prática deliberada na fase de análise é a antecipação também já provavelmente coberta em etapas anteriores da 
formação do intérprete, mas que deve ser reforçada do ponto de vista da simultânea. O objetivo é o aluno desenvolver uma percepção aguçada das escolhas prosódicas, sintáticas e lexicais do orador e de pistas contextuais presentes no discurso original que permitam antecipar a continuidade do fluxo de ideias. Vale observar que a prática da antecipação contextual pode ser atrelada ao desenvolvimento da competência extralinguística discutido anteriormente como fator redutor de stress.

A etapa intermediária entre compreensão e produção inclui aqui a noção de tomada de decisão no intuito de esclarecer que os processos característicos desta fase provocam um atraso variável, porém inevitável, na produção. Essa defasagem, conhecida por décalage, faz parte da essência da interpretação simultânea e, segundo Pöchhaker (2004, p. 117), será diretamente proporcional à complexidade das decisões a serem tomadas. Ilustrativamente, se o orador disser "good morning", a decisão será simples e rápida e a defasagem, quase imperceptível. Se, pelo contrário, o orador emitir um conceito obscuro com sintaxe complexa e vocabulário incomum, a defasagem será inevitavelmente maior.

Portanto, nessa fase são válidas todas as atividades de prática que ajudem o aluno a entender as consequências da maior ou menor defasagem entre compreensão e produção e fazer os ajustes necessários. 


\section{Aspectos da fase de produção}

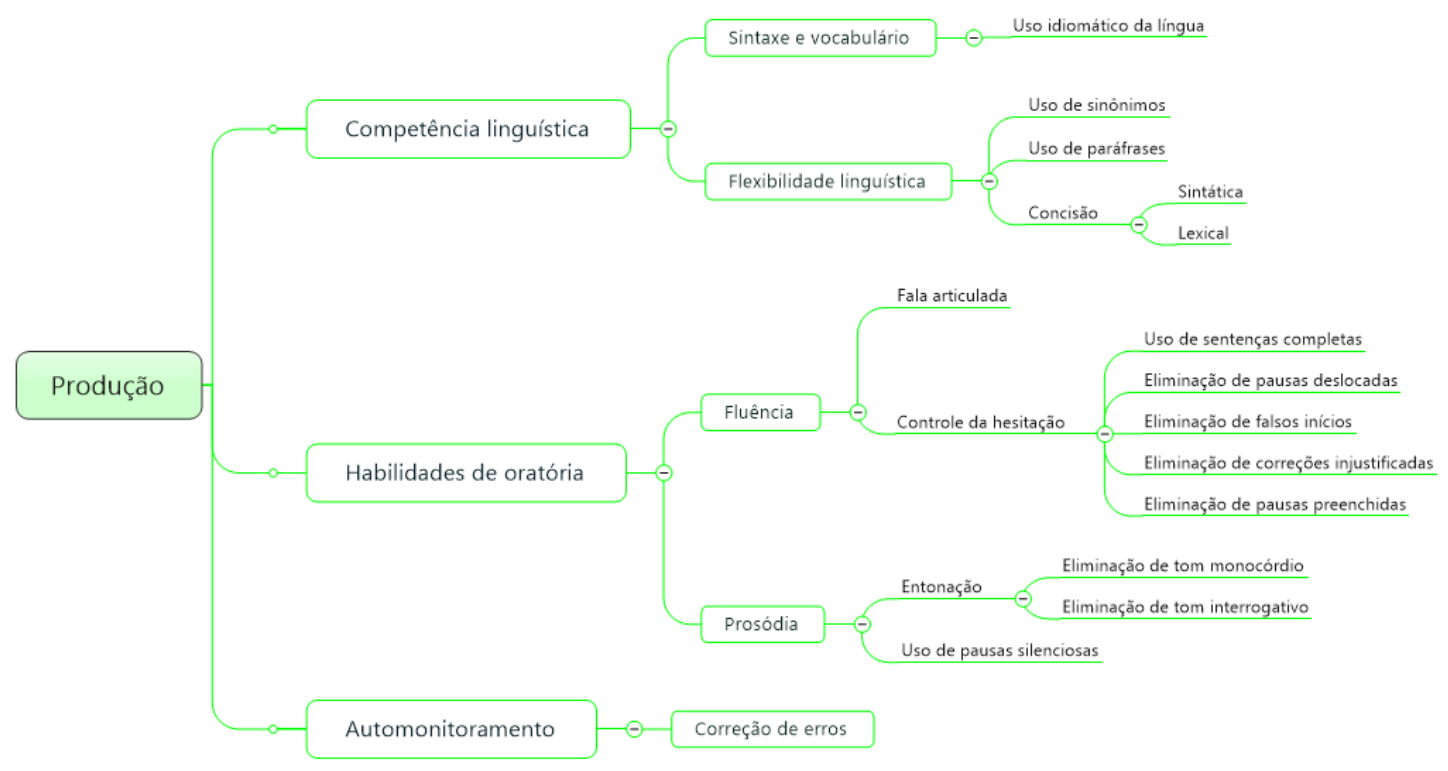

Os componentes da produção tendem a ser o enfoque da maioria dos exercícios de prática deliberada precisamente por ser esta a única manifestação perceptível do que ocorreu nas fases anteriores. Gravações e transcrições são ferramentas úteis para esse fim, pois permitem uma análise metacognitiva do produto final que aumentará a conscientização do aluno sobre os vários aspectos a serem dominados no percurso rumo à expertise em interpretação.

No grupo de competência linguística, a prática concentra-se em escolhas sintáticas e lexicais idiomáticas, evitando-se, assim, uma produção que cause estranhamento ao ouvinte. Além disso, o aluno deve desenvolver um arsenal flexível de soluções linguísticas que agilizem a produção. Nesse sentido, ênfase especial deve ser dada à prática de concisão na escolha de estruturas e expressões para que a produção resulte mais enxuta, rápida e precisa.

Quanto à oratória, que provavelmente terá sido trabalhada desde o início da formação, na simultânea a principal ênfase será lapidar habilidades para que o output seja claro e fluente mesmo sob o estresse da impossibilidade de controlar o input do orador. 
O grupo de controle de hesitação merece destaque, pois é importante que o aluno entenda que hesitações são inevitáveis na interpretação simultânea sempre que o intérprete precisa ganhar tempo. A causa mais provável da hesitação é uma análise falha ou precipitada. Praticar uma boa segmentação com frases curtas, completas e bem controladas, delimitadas por pausas silenciosas, costuma ser a solução que o intérprete precisa em seu arsenal para ter tempo suficiente para reformular sem hesitar.

Por fim, o auto monitoramento merece ênfase em exercícios de prática deliberada para que o aluno se conscientize da necessidade ou não de corrigir erros e seja capaz de avaliar a eficácia das correções feitas.

\section{A alternância de ênfase}

A vantagem da alternância de ênfase proposta por De Groot (2000) é liberar o professor do compromisso com a prática dos aspectos propostos acima em uma determinada sequência, pois parece irrelevante e improdutivo tentar decidir, só para citar um exemplo, se o uso de estruturas sintáticas mais concisas é mais ou menos importante e deve anteceder ou suceder a eliminação de correções injustificadas no aprendizado da interpretação.

Igualmente irrelevante seria se ater à ordem compreensão - análise produção. Nada impede, também como exemplo, que um aspecto da produção, como produzir frases completas, seja praticado antes de se abordar os componentes da competência extralinguística que são parte da compreensão.

\section{Formulário de feedback}

O formulário de feedback proposto neste artigo resulta de cerca de cinco anos de tentativas para chegar a um modelo simples, intuitivo e, espera-se, eficaz. O esqueleto básico foi mantido ao longo dos anos, mas versões mais detalhadas que pretendiam refletir uma suposta hierarquia dos diferentes aspectos a serem praticados pelo aluno foram abandonadas por se revelarem inúteis.

$\mathrm{O}$ atual formulário agrupa aspectos do processo de interpretar que se tornam evidentes no produto da interpretação. A intenção é usar uma 
versão única para feedback somativo ou formativo dado pelo professor, ou pelos alunos para fins de autoavaliação, feedback entre pares ou feedback ipsativo. Reforça-se, assim, a ideia de que o aluno pode ser capaz de usar as mesmas ferramentas do professor e se apropriar de sua avaliação.

A estrutura adotada baseia-se no argumento de Schjoldager (1996) de que a principal utilidade de um formulário de feedback é servir de ponto de partida para uma discussão produtiva sobre o desempenho do aprendiz.

O formulário começa com aspectos positivos não só no intuito de estabelecer uma atmosfera de receptividade a essa discussão, mas também para mostrar ao aluno que pontos de seu desempenho já atingiram nível satisfatório, bastando, portanto, mantê-los.

A partir daí os aspectos a serem avaliados foram estruturados, também como sugere Schjoldager (1996), na ordem em que a produção de um intérprete tende a ser percebida pelo ouvinte. As características prosódicas são notadas antes do uso da língua ou de defeitos de fluência; a fidelidade à mensagem original vem em seguida, e a competência extralinguística completa o formulário.

A escala de 1-5 serve como uma rubrica simplificada, sendo 5 o desempenho esperado de um expert. Assim, a indicação de um 3, por exemplo, sinaliza o tamanho da lacuna entre o desempenho atual e o almejado. Evita-se, com isso, rubricas excessivamente detalhadas e complexas que podem até ser úteis em exames de interpretação (Setton e Dawrant, 2016, p. xxxx), mas parecem dispensáveis na rotina de sala de aula.

A última coluna do formulário destina-se à anotação de exemplos ilustrativos que ajudem o aluno a compreender exatamente como está se desempenhando em cada categoria.

Ao final, o formulário prevê que o responsável pelo feedback indique aspectos dignos de melhoria e inclua sugestões sobre como essa melhoria pode ser alcançada. Quando preenchido por um aluno, a ideia é, se possível, esse espaço servir para que colegas compartilhem entre si soluções eficazes que já fazem parte de seu "arsenal". 


\begin{tabular}{|c|c|c|c|c|c|c|c|c|}
\hline \multicolumn{8}{|l|}{$\begin{array}{l}\text { Nome do aluno:Avaliador: } \\
\text { Ponto(s) positivo(s) observado(s): }\end{array}$} & Identificação da atividade: \\
\hline CARACTERÍSTICA & \multirow[t]{2}{*}{ DESEJÁVEL } & + & & & & 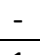 & \multirow{2}{*}{ INACEITÁVEL } & \multirow{2}{*}{ EXEMPLOS } \\
\hline \multicolumn{6}{|l|}{ COMUNICAÇÃO } & & & \\
\hline Articulação & clara & & & & & & dificulta compreensão & \\
\hline Entonação & compatível com orador & & & & & & incompatível com orador & \\
\hline \multicolumn{8}{|l|}{ COMPETÊNCIA LINGUÍSTICA } & \\
\hline Sintaxe & correta / idiomática & & & & & & incorreta / não idiomática & \\
\hline Escolha vocabular & adequada/idiomática & & & & & & inadequada/ não idiomática & \\
\hline \multicolumn{8}{|l|}{ FLUÊNCIA } & \\
\hline Ritmo & regular & & & & & & irregular & \\
\hline $\begin{array}{l}\text { Hesitações / sentenças } \\
\text { incompletas }\end{array}$ & raras & & & & & & frequentes & \\
\hline Pausas & silenciosas/bem posicionadas & & & & & & preenchidas / deslocadas & \\
\hline Fillers / prolongamentos ("ruídos") & raros & & & & & & frequentes & \\
\hline Correções & claras/justificadas & & & & & & confusas/desnecessárias & \\
\hline \multicolumn{8}{|l|}{ FIDELIDADE } & \\
\hline Intenção/emoção do orador & preservada & & & & & & perdida & \\
\hline Lógica da mensagem & preservada & & & & & & perdida & \\
\hline Alterações de sentido & raras & & & & & & frequentes & \\
\hline Omissões & menores/deliberadas & & & & & & graves & \\
\hline \multicolumn{8}{|l|}{ COMPETÊNCIA EXTRALINGUÍSTICA } & \\
\hline Preparação do tópico/terminologia & evidente & & & & & & insuficiente & \\
\hline Conhecimento cultural/ contextual & evidente & & & & & & insuficiente & \\
\hline
\end{tabular}

Ponto(s) a melhorar:

\section{Como melhorar:}


Para concluir, vale enfatizar que, em linha com o conceito de prática deliberada sugerido neste artigo, não se espera que todas as categorias sejam cobertas em uma mesma atividade, ficando a cargo de professor e alunos alternar a ênfase entre as várias categorias para atender necessidades individuais ou coletivas da turma.

\section{Considerações finais}

Este artigo pretendeu atender o convite de Tiselius (2013, p. 13) para uma adaptação da definição de expertise e da aplicabilidade do conceito de prática deliberada à aquisição da habilidade de interpretar. A motivação para esse convite foi a constatação pela mesma autora que intérpretes classificados como experts não empregavam a prática deliberada conscientemente como ferramenta de melhoria contínua. Ocorre que, antes de concluirmos que a prática deliberada é inútil ou dispensável na aquisição de expertise em interpretação, talvez valha observar que Tiselius analisou profissionais cuja formação se deu provavelmente em meados de 1990, quando os estudos de Ericsson sobre prática deliberada em outras habilidades ainda eram recentes e o artigo mais específico onde Ericsson discute a habilidade de interpretar (2000) nem tinha sido publicado. Ou seja, parece lógico supor que os experts em interpretação observados por Tiselius jamais foram expostos ao uso sistemático da prática deliberada seguida de feedback durante a formação e, talvez por isso, acabaram por desenvolver expertise de forma aleatória.

Já se a prática deliberada for adotada sistematicamente, conforme aqui sugerido, experiências empíricas parecem revelar que alunos expostos a esse cenário pedagógico recente tendem a desenvolver maior consciência sobre como praticar e se desenvolver continuamente com auxílio da prática deliberada, de feedback e de ferramentas de metacognição. Este artigo pressupõe que essa apropriação do aprendizado representa uma maior garantia de se chegar à expertise por vias consistentes e não por acaso.

Estudos futuros seriam necessários para avaliar a real eficácia desta abordagem como facilitadora da formação de experts em interpretação e dados sólidos a respeito poderiam, inclusive, influenciar a duração de cursos de interpretação. Ficando comprovado que o aluno é efetivamente capaz de se apropriar de sua melhoria contínua, Dillinger (1994, p. 185) pode estar certo ao dizer que, supondo-se conhecimento linguístico prévio suficiente, cursos de interpretação simultânea não precisam ser longos, nem complexos. Do contrário, talvez Setton e Dawrant (2016, p. 529) tenham razão de achar que nem mesmo as 800 horas preconizadas pelo EMCI são suficientes para equipar um iniciante com o mínimo necessário para ingressar no mercado e muitas mais são necessárias para que esse iniciante venha a ser reconhecido como expert na habilidade de interpretar. 


\section{Referências}

BARGHOUT, A.; ROSENDO, L. R.; GARCÍA, M. V. The influence of speed on omissions in simultaneous interpretation: An experimental study. Babel, 61(3), p. 305334, 2015.

BOURNE, L.; KOLE, J.; HEALY, A. Training Principles to Advance Expertise. Frontiers in Psychology, 2014.

DE GROOT, A. A complex-skill approach to translation and interpreting. In TIRKONNEN-CONDIT, S.; JÄÄSKELÄINEN, R. (eds.). Tapping and Mapping the Processes of Translating and Interpreting. Amsterdam: John Benjamins, 2000, p. 5370 .

DILLINGER, M. Comprehension during interpreting: What do interpreters know that bilinguals don't. In: LAMBERT, S, MOSER-MERCER, B. (eds). Bridging the gap: Empirical research in simultaneous interpretation. Amsterdã: John Benjamins, 1994. p. $155-189$.

ERICSSON, K.; KRAMPE, R.; TESCH-RÖMER, C. The role of deliberate practice in the acquisition of expert performance. Psychological Review, 100(3), p. 363-406, 1993.

ERICSSON, K.; CHARNESS, N. Expert performance: Its structure and acquisition. American Psychologist, 49(8), p. 725-747, 1994.

ERICSSON, K. Expertise in interpreting: An expert-performance perspective. Interpreting, 5(2), p. 187-220, 2000.

. How the Expert Performance Approach Differs From Traditional Approaches to Expertise in Sport: In Search of a Shared Theoretical Framework for Studying Expert Performance. In: STARKES, J. ERICSSON, K. (eds). Expert performance in sports: Advances in Research on Sport Expertise. Champaign, IL: Human Kinetics, 2003. p. 371-402.

- Training History, deliberate practice and elite sports performance: an analysis in response to Tucker and Collins review - what makes champions? British Journal of Sports Medicine, 47:9, p. 533-535, 2013.

FLAVELL, J. Metacognitive aspects of problem solving. In: RESNICK, L. (ed.) The nature of intelligence (12). Hillsdale: Lawrence Erlbaum Associates, 1976. p. 231-235

GILE, D. Basic concepts and models for interpreter and translator training. Amsterdã: John Benjamins, 2009.

GILLIES, A. Note-taking for consecutive interpreting. Manchester: St. Jerome Pub, 2005. 
JIANG, H., NORVELE, I. Skill Transfer from CI to SI, Universidade de Genebra. Disponível em: http://archive-ouverte.unige.ch/unige:28296, Acesso em 22 de novembro 2017.

JOHNSON, J. Mental Conditioning for Interpreters. Found in Translation Series, Middlebury Institute of International Studies at Monterey. Disponível em: https://www.youtube.com/watch?v=ImtbRHJSDU4, Acesso em 22 de novembro 2011.

KALINA, S. Interpreting competences as a basis and a goal for teaching. The Interpreters' Newsletter (10), Trieste, 2000.

LIU, M. How do experts interpret? Implications from research in Interpreting Studies and cognitive science. In: GYDE, H; CHESTERMAN, A; GERZYMISCH-ARBOGAST (eds). Efforts and Models in Interpreting and Translation Research. Amsterdã, John Benjamins. 2009. p.159-177.

MACNAMARA, B. et al. Domain-general cognitive abilities and simultaneous interpreting skill. Interpreting, 13(1), p. 121-142, 2011.

MOSER-MERCER, B. Skill Acquisition in Interpreting. The Interpreter and Translator Trainer, 2(1), p. 1-28, 2008.

MOSER-MERCER, B. et al. Searching to Define Expertise in Interpreting. IN: DIMITROVA, B.; HYLTENSTAM. K. (eds). Language Processing and Simultaneous Interpreting: Interdisciplinary perspectives, Amsterdã: John Benjamins. 2000. p.107132.

PÖCHHAKER, F. Introducing Interpreting Studies. Londres: Routledge. 2004.

RAMAPRASAD, A. On the definition of feedback. Systems Research and Behavioral Science, 28(1), p. 4-13, 1983.

RICCARDI, A. On the Evolution of Interpreting Strategies in Simultaneous Interpreting. CLAS, A. (ed). Meta: Translators' Journal (50-2), p. 753-767, 2005.

SAWYER, D. Fundamental aspects of interpreter education: Curriculum and assessment. Amsterdã: John Benjamins, 2004.

SCHJOLDAGER, A. Assessment of Simultaneous Interpreting. Teaching translation and interpreting (3), p. 187-196, 1996.

SHLESINGER, M. Interpreting as a Cognitive Process: How can we know what really happens? In TIRKONNEN-CONDIT, S.; JÄÄSKELÄINEN, R. (eds.).In: Tapping and Mapping the Processes of Translating and Interpreting. Amsterdam: John Benjamins, 2000, p. 3-15.

SETTON, R. Use of theory in interpreter training. AIIC Webinar, 2012. [link inativo] SETTON, R., DAWRANT, A. Conference Interpreting: A Trainer's Guide. (Vol. 120). Amsterdã: John Benjamins, 2016.

TISELIUS, E. Expertise without deliberate practice? The case of simultaneous interpreters. The Interpreters' Newsletter. 18, p. 1-15, 2013. 


\title{
Resumo
}

Segundo Ericsson, o caminho rumo à expertise passa pela prática deliberada. Segundo Tiselius, o fato de intérpretes experts aparentemente não adotarem a prática deliberada como ferramenta de melhoria contínua demanda tanto uma redefinição de expertise quanto do conceito prática deliberada sob a ótica da interpretação. Este artigo pretende atender o convite de Tiselius e, para fins pedagógicos, propõe uma visão alternativa dos conceitos de expertise e de prática deliberada possivelmente útil para formação de alunos aptos a se apropriar do próprio desenvolvimento rumo à expertise.

Palavras-chave: expertise, interpretação simultânea, prática deliberada, feedback, prática autônoma

\begin{abstract}
Ericsson advocates that expertise is achieved via deliberate practice. Tiselius, in turn, observed that expert interpreters do not necessarily use deliberate pratice as a continuous improvement tool, which may mean that both deliberate practice and expertise need to be redefined in light of the specificities of interpreting. Inspired by the arguments introduced by Tiselius, this article proposes an alternative view of expertise and deliberate practice which may be of pedagogical use to empower students to continuously develop towards expertise in interpreting.

Keywords: expertise, simultaneous interpreting, deliberate practice, feedback, independent learning
\end{abstract}

